\title{
Screening collection varieties of VIR for resistance to stress factors (resistance to diseases and lodging) at Novosibirsk region
}

\author{
Boyko N.I. ${ }^{1 *}$, Aparina V.A. ${ }^{1}$, Sukhomlinov V.Yu. ${ }^{1}$, Zuev E.V. ${ }^{2}$, Piskarev V.V. ${ }^{1}$ \\ ${ }^{1}$ Siberian Research Institute of Plant Production and Breeding - Branch of the Institute of Cytology \\ and Genetics, SB RAS, Novosibirsk, Russia \\ ${ }^{2}$ Federal Research Centre the N.I. Vavilov All-Russian Institute of Plant Genetic Resources, \\ St. Petersburg, Russia \\ * email:n.bojko@mail.ru
}

Collection varieties of spring soft wheat (Triticum aestivum L.) from The N.I. Vavilov All-Russian Institute of Plant Genetic Resources was studied in Siberian Research Institute of Plant Production and Breeding - Branch of the Institute of Cytology and Genetics, SB RAS. Fifty new varieties are received annually. They are sown manually in the first year, then, the varieties are studied on plot $\left(2 \mathrm{~m}^{2}\right)$ for three years. The collection of varieties is compared with the standards: Novosibirskaya 15 (early ripeness), Novosibirskaya 31 (mid-early ripeness), Obskaya 2 (mid ripeness), Sibirskaya 17 (mid-late ripeness). The appropriation of the varieties to the ripeness group carried out in the first year of sowing. The field assessment for resistance to biotic factors (Blumeria graminis and Puccinia triticina) carried out using the VIR method under natural infection conditions. The weather conditions of 2018-2019 were favorable for the development of powdery mildew and leaf rust. During the period 2018-2019 years 161 varieties were studied, 21 from which characterized by resistance to leaf rust and 7 to powdery mildew for 2 years. Varieties Sparrow (K-66090) and LD25 (Saratov Research Institute South-East) were not affected by leaf rust and powdery mildew (score - 99). Lodging rating of varieties from this collection were studied. The evaluation indicated that $39.8 \%$ (64 varieties) were characterized by very high resistance to lodging (score - 9), variety NIL Thatcher Lr45 (66210) was not resistance to lodging (score 3 and 5). At the same time, the maximum yield $\left(629.3 \mathrm{~g} / \mathrm{m}^{2}\right)$ in 2018 was formed by the variety Sigma 2 (k-65999), which was characterized by high resistance to leaf rust (score 7 ), powdery mildew (score 99) and resistance to lodging (score 9). The maximum yield $\left(620.8 \mathrm{~g} / \mathrm{m}^{2}\right)$ in 2019 was formed by the variety M83-1591 (66234), which was characterized by medium resistance to leaf rust (score 5), medium and high resistance to powdery mildew (score $5 ; 7$ ) and medium and high resistance to lodging (score $5 ; 7$ ). Acknowledgements: This work was supported by ICG SB RAS budget project No. 0259-2021-0018. 